\title{
The Effects of Vocabulary Learning on Taiwanese College Students' Writing
}

\author{
Tai Feng-Chen
}

\begin{abstract}
This study investigates two approaches of vocabulary learning: productive and receptive and their effectiveness in facilitating Taiwanese college students' writing. Participants were 99 first-year college students. One half was assigned to learn a set of 20 target words productively through word pairs and the other receptively. A post picture-based writing task was used to measure writing quality and the number of target words, and a vocabulary test, productive vocabulary knowledge. The results showed that the productive group outperformed the receptive group in writing quality, the number of target words and productive vocabulary knowledge. The findings suggest that productive vocabulary learning through word pairs may be more effective than the receptive method.
\end{abstract}

Key words: vocabulary learning, writing, word pairs, productive, receptive

\section{Introduction}

For students in Taiwan where English is learned as a foreign language (EFL), writing has been a very challenging task. In terms of writing, a dearth of vocabulary has been one of students' major obstacles. Researchers point out a lack of vocabulary may result in greater writing difficulties for foreign language learners (Astika, 1993; Lee 2003; Muncie, 2002). Nation (2003) suggests if students first learn a few new words which are relevant to the topic, there is a high possibility that they may use those words in their post-written task. Lee (2003) also suggests that vocabulary instruction may be an approach for writing instruction especially at the initial stages. Thus, with an attempt to solve the difficulty of lacking vocabulary while writing, this study aims to investigate the effects of the two methods of vocabulary learning on Taiwanese college students' writing.

Pre-learning vocabulary might have some positive effects on writing in the first language (L1) (Graves, 1986; Dune and Graves, 1987). In Duin and Graves's (1987) experiments, they found that the students who were pre-taught some words relevant to their post essay task showed improvement in their writing quality. Their findings also showed that the group that received both intensive vocabulary and writing instruction prior to the writing task gained better results than the groups of intensive vocabulary instruction (without writing 
instruction) and the traditional vocabulary instruction. In Yonek's (2008) experiment, the effectiveness of rich and traditional instruction on students' composition was studied. Rich vocabulary instruction included contextual information, deeper understanding and multi-exposures of words, while traditional instruction consisted of basic dictionary definition and cloze sentences writing. Yonek (2008) found that the group that received rich instruction prior to writing outperformed the group that received traditional vocabulary instruction. As for second language (L2), studies have shown that students who received pretaught words instruction used more target words in their writing than students who did not receive pre-taught words instruction (Lee, 2003, McDaniel \& Pressley, 1984, 1989). In Lee's (2003) experiment, the students used more target words in a writing task after receiving a variety of deliberate vocabulary instruction. In addition, delayed writing showed no significant loss of target words. The evidence both in L1 and L2 indicates that students may benefit from vocabulary instruction prior to their writing task.

Language skills are often classified into two types in terms of thir use: productive and receptive. Writing and speaking are categorized as productive use of language, while reading and listening are receptive. To use vocabulary receptively in reading or listening and productively in writing or speaking signify two different abilities (Henriksen, 1999). Different methods of vocabulary learning may affect the development of language skills.
Learners thus are advised to adopt learning methods accordingly for varied purposes of language communication, whether understanding words for reading or producing vocabulary for writing.

Learners use their productive knowledge to produce a word form when writing or speaking, and receptive knowledge to understand a word's meaning when reading or listening (Nation, 2001; Schmitt, 2000). Studies have shown that learning vocabulary productively can effectively increase productive knowledge (Waring, 1997; Webb, 2009). In addition, learning vocabulary productively by word pairs can be more suitable than learning vocabulary receptively in terms of developing students' productive knowledge and facilitating their writing (Webb, 2009). In Webb's (2009) experiments, two groups of students learned 15 fabricated word pairs prior to a picture-based writing test. The group of students who received productive learning of vocabulary used an average of $42 \%$ of the target words in sentences, which was much higher than the other group of students who learned the vocabulary receptively and wrote only $29 \%$. Productive learning helped students develop productive knowledge and skills, which were required for writing.

While intensive or rich vocabulary instruction has shown its positive effects on writing, the effectiveness or ineffectiveness of the de-contextualised and efficient vocabulary learning has not yet been determined and remaines to be explored (Webb, 2009).Researchers

$54 \quad$ Journal of NELTA, Vol 18 No. 1-2, December 2013 
have found that explicit vocabulary learning such as word pairs may be an effective and efficient vocabulary learning method (Nation, 2003; Webb, 2009; Prince 1996). Learning by word pairs indicates students learning L2 word on one side and L1 translation on the other side of a card or a piece of paper (Nation, 2003).Prince (1996) suggests that students can memorize L2 words better because of the L1 equivalents (p.479). Lee (2003) also suggests that explicit vocabulary instruction would help learners be aware of the words so as to utilize them in their writings.

Although productive learning seems to be a more effective method in improving students' writing, the receptive approach is still prevailed in classroom instruction (Webb, 2005). Likewise, in Taiwan, the receptive approach has been widely adopted for vocabulary learning in many English classrooms. Taiwanese students usually learn words based on textbook in a traditional way and most of the time in the classroom. Traditional vocabulary instruction means teachers would provide a word based on the textbook translating its meaning in L1. Sometimes, teachers would demonstrate the word in sentences, pronounce the word, or ask students to repeat the sound of the word after them. By and large, students are taught to remember the meaning of a word and hardly have time to practice the spelling of the word or use it productively in writing tasks.

Writing has attracted broad attention in Taiwan, since the General English
Proficiency Test (GEPT) supported by Taiwan's government includes writing as one of its testing items. However, students in Taiwan often face great challenges such as spelling, grammar, phrases and, most of all, vocabulary in writing (Joe, 2005; Chen \& Yeh, 2004). According to Joe's (2005) investigation, the average vocabulary size of the firstyear technological college students in Taiwan was about 1000 words. The highest number of words achieved by some students was about 2,500 words, while some could not reach 500 words (Joe, 2005). If grammar received much more attention than vocabulary in the classroom teaching, it often would lessen EFL students' learning interests and reduce the effect of communicative language use of writing. Prince (1996) mentions that possessing "adequate and appropriate vocabulary" (p.478) outweighs "the mastery of grammatical rules" in terms of effective communication. Thus, to assist Taiwanese college students in learning vocabulary would be crucial to improve their writing.

\section{Research questions}

This study investigated two methods to vocabulary learning - productive and receptive, and their effectiveness in assisting Taiwanese college students' writing. The research was designed to explore the following research questions:

1. Do students who learn vocabulary productively from word pairs use more target words than students who learn vocabulary receptively, in a post picture-based composition? 
2. Do students who learn vocabulary productively from word pairs have higher scores than students who learn vocabulary receptively in writing quality in a post picturebased composition?

3. Do students who learn vocabulary productively from word pairs have higher scores in the test of productive vocabulary knowledge than students who learn vocabulary receptively?

\section{Methodology}

\section{Participants}

The participants were 99 first-year Taiwanese college students. Most of the students had graduated from vocational high schools. They had a low level of English proficiency with a vocabulary size below 1000. Before they entered the college, they had to take an Entrance Examination in Technological and Vocational Education. The results generally decided which school they could attend. Thus, the participants had a similar learning background and English proficiency. The students normally received three hours of general English training per week for two and half months in each semester for one year. There were two semesters in one year. The students' native language was Chinese, which was mainly adopted for classroom instruction, while English was hardly used.

\section{Design}

The participants were randomly split into two groups. One group of 49 students was assigned to learn a set of
20 target words productively and the other group of 50 receptively. Before conducting word pairs learning, the teacher first introduced the 20 target items with their translations, sounds and some examples in sentences on the blackboard. The time for this instruction was about 20 minutes. Then, each student was given a piece of A4 size paper divided into two columns with L2 items printed on the left and L1 translations on the right (see Appendix 1). The receptive group was instructed to fold the paper into two halves, look at the left column of target words first and then recall the meaning in L1. They were told only to flip the paper over to the Chinese translations when they forgot the meanings. However, unlike receptive group, the productive group in this step was told to look at the righthand column of L1 translations first, and then recall the spelling in L2.The time for word pairs learning was about 20 minutes.

Two post-tests were administered immediately after the treatments. The procedures were the same for the two groups. The first test was a picturebased writing task based on a selected theme-"Diet" (see Appendix 2). The topic was chosen because it had a direct appeal to the young Taiwanese college students. The writing topic consisted of three pictures presented in chronological order. The students were given the following instruction in Chinese: "Joe was laughed at by his classmates because of being fat. Write a 50-word short story based on the three sequential pictures". The second test, administered after the first writing task, was on productive knowledge (see 
Appendix 3). The set of the 20 target words was presented in L1 and the students were told to write their equivalent words in English. The time for each test was about 15 to 20 minutes.

\section{Target words}

All the target words were taken from the students' textbook "Smart Choice I" used for their English course. The level of Smart Choice 1 equals to TOEFL CBT 137-173, TOEIC 500-650 or IELTS3.04.0. Eleven single words and nine multiword strings related to the topic "Diet" were selected (see Appendix 4). Students were encouraged to use the target words in their writing so as to demonstrate their ability of employing new vocabulary and knowledge of new words.

\section{Measurements}

There were two tests. First, a picturebased writing test was administered to measure the number of target words used in writing and the quality of writing. The correct spellings of the target items were counted by the researcher and checked by another teacher. Minor errors of spelling were given credit if the word was recognizable and appropriately used in their writing. Each word or word combination was counted only once. The score of writing quality was based on the Taiwan GEPT Primary Writing Rating Scale (0-5)(LTTC, Taiwan, 2009) as shown in Appendix 5. A score of 5 represents the highest grade and 0 the lowest. The writing task was pencil and paper test. All the writings were scored by two non-native teachers. The disagreement on the scores was resolved and arrived at an agreement with a third non-native rater. A picture-based writing task was chosen because it was more conspicuous and easier to determine the students' ability of using the target words (Webb, 2009). Second, a translation vocabulary test was used to measure learners' productive knowledge. L1 translation was offered in the test and the students were required to write the equivalent target words. The vocabulary test of the 20 target words (0-20) was scored by the researcher and checked by the other teacher.

\section{Results}

The results of the two groups at the writing task and the vocabulary test on the number of target words used, quality of writing and productive vocabulary knowledge are presented below.

\section{Number of target words used in writing}

The data for the number of target words used by the students are shown in Table 1.

Table 1: Mean score and standard deviations of target words used in writing by two groups

\begin{tabular}{|c|c|c|c|c|}
\hline \multirow{3}{*}{ 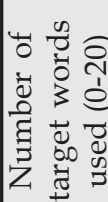 } & Group type & $\mathrm{N}$ & Mean & Std. Deviation \\
\hline & productive & 49 & 8.76 & 4.475 \\
\hline & receptive & 50 & 6.70 & 4.292 \\
\hline
\end{tabular}

The results indicate that productive vocabulary learning may be more effective than that of the receptive one on the number of target words used. As can be seen, the productive learner 
had a mean score of $8.76(\mathrm{SD}=4.475)$, while the receptive learners had a lower mean score of $6.70(\mathrm{SD}=4.292)$ on the number of target words used in writing. To test whether there were any differences between the two methods and the number of the target words used by the two groups, an independent samples t-test was applied. The difference was found to be statistically significant between the learning methods and the number of target words used by the participants in a post-writing task $(\mathrm{p}=0.022$, $\mathrm{t}=2.332, \mathrm{df}=97)$. The difference is shown in Figure 1.

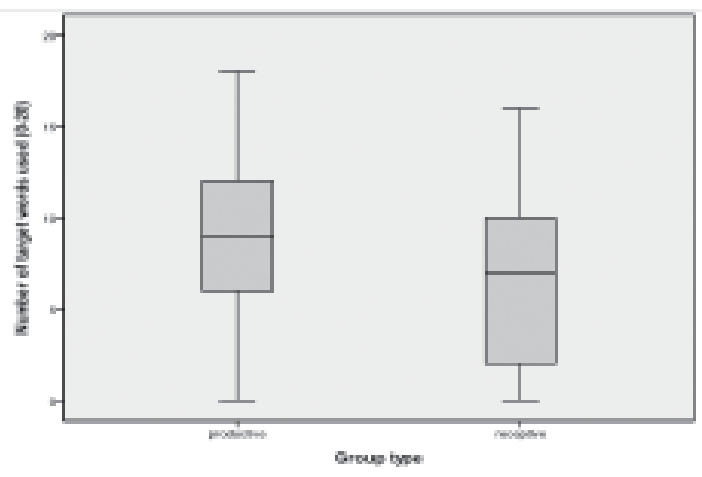

Figure 1: Productive and receptive differences in the number of target words used in writing

\section{Quality of writing}

The experiment was intended to test whether productive or receptive vocabulary learning can facilitate students' writing effectively. A MannWhitney U Test was performed to determine whether there were any differences between the treatment groups. The difference was found to be statistically significant between the scores of the writing quality in relation to the productive and the receptive learning that the students achieved $(\mathrm{p}=$ 0.009, Mann-Whitney $\mathrm{U}=861$,
$Z=2.618)$. It indicated that productive learning from word pairs may be more effective than receptive learning in improving writing. In addition, as can be seen in Table 2, the students who completed productive word-pairs task had higher scores on the picture-based writing task than the receptive group. For instance, $40.8 \%$ of the productive learners achieved above the scale of 3 compared to $20 \%$ of receptive learners on the quality of writing. The difference is shown in Figure 2 below.

Table 2:Writing quality scores achieved by productive and receptive groups

\begin{tabular}{|rrrcr|}
\hline $\begin{array}{r}\text { Rating } \\
(0-5)\end{array}$ & \multicolumn{2}{c}{ Productive Group } & \multicolumn{2}{r|}{ Receptive Group } \\
5 & 0 & 0.0 & 1 & 2.0 \\
4 & 5 & 10.2 & 1 & 2.0 \\
3 & 15 & 30.6 & 8 & 16.0 \\
2 & 12 & 24.5 & 12 & 24.0 \\
1 & 12 & 24.5 & 15 & 30.0 \\
0 & 5 & 10.2 & 13 & 26.0 \\
Total & 49 & 100.0 & 50 & 100.0 \\
\hline
\end{tabular}

Note: Rating 5 represents the highest score and 0 the lowest.

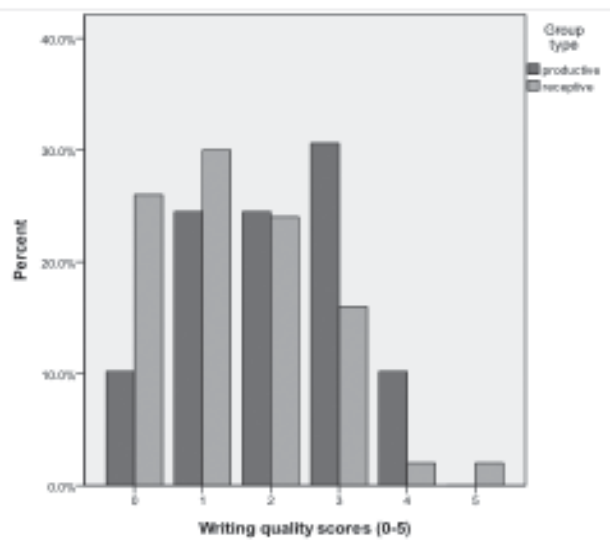

Figure 2: Productive \& receptive differences in the writing quality scores 


\section{Productive vocabulary knowledge}

The data for the test on the students' productive vocabulary knowledge has been shown in the table below.

Table 3: Mean score and standard deviations on productive test of vocabulary knowledge

\begin{tabular}{|c|c|c|c|c|}
\hline \multirow{3}{*}{ 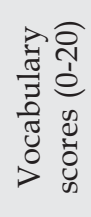 } & Group type & $\mathrm{N}$ & Mean & Std. Deviation \\
\hline & Productive & 49 & 13.51 & 5.519 \\
\hline & Receptive & 50 & 7.66 & 5.568 \\
\hline
\end{tabular}

Note: *Maximum score was 20

As can be seen, when the test was administered with 20 full marks, the productive learner had a mean score of 13.51(SD=5.519) while the receptive learners had a much lower mean score of $7.66(\mathrm{SD}=5.568)$ on the test of productive knowledge of vocabulary. The result of an independent sample ttest produced evidence of a difference between the productive and the receptive vocabulary learning methods on the test of productive knowledge of vocabulary. $(\mathrm{p}<0.001, \mathrm{t}=5.249, \mathrm{df}=97)$. The difference is shown below in Figure 3. The condition of productive learning had a higher rate of vocabulary scores on test of productive knowledge.

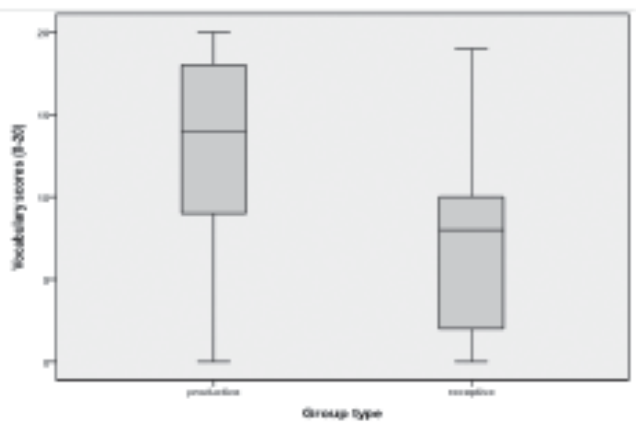

Figure 3: Productive $\mathcal{E}$ receptive differences in the productive knowledge of target words

\section{Discussion}

The students' performances in the writing task and the vocabulary test of the two conditions were compared on the basis of the number of target words used, the quality of their writing and their productive vocabulary knowledge. The discussion is based on the findings in relation to the three research questions respectively. For the first research question on the number of target words used in writing, the participants of the two groups all demonstrated that they were capable of using the target words in their post writing tasks after receiving vocabulary instructions accordingly. It shows that learning vocabulary through word pairs may facilitate writing. The students who learned vocabulary productively used an average of $43.8 \%$, while the students who learned vocabulary receptively wrote an average of $33.5 \%$. The outcome indicated that productive learning of word pairs might have a greater impact on writing than that of receptive learning. Webb (2009) suggested that the transfer effect from productive learning made a contribution to the positive effect on writing. That is, productive learning and writing both involve an almost identical process of recalling the word form of L2; in contrast, receptive learning only involves recalling the meaning of the word.

As for the second research question regarding the effect of vocabulary learning on the quality of writing, the results revealed that the students who received productive instruction performed better than those who received receptive instruction. For example, $40.8 \%$ of productive group learners achieved above the scale of 3 whereas only $20 \%$ of the receptive 
learners achieved this level. In addition, the productive group used more target words in writing than the receptive group. Thus, the outcome of the writing quality corresponds to the number of the target words used in both groups. The more target words the students used, the higher rate they achieved.

Although the results showed that the productive learners were able to use more target words in writing than the receptive learners, the average scores for both groups were not high. As shown in Table 2, almost $60 \%$ of productive learners and $80 \%$ of receptive learners scored below the scale 3, which was an indicator of poor writing. Only $10 \%$ of the productive group and $4 \%$ of the receptive group were able to use the target words appropriately and correctly to describe a story about the pictures. Writing has been considered a complex task; it would be a challenging task for EFL learners to use the newly learned words in writing in short time. Except for producing word forms while writing, students also need to have knowledge of other aspects of words such as syntax, semantics, and grammar (Webb, 2009). Since all the participants were novice writers, they might have a small size of vocabulary, little experience and low ability in writing. Furthermore, the research showed that some students just piled up some target words to describe the pictures rather than sentences. It indicated that the participants would require more writing practices and instruction.

The third question investigated the relative effect of productive and receptive learning of word pairs for productive knowledge. The students who completed the productive task scored $67.5 \%$, which is almost double of the receptive group's $38.3 \%$ on the test of productive knowledge. The results suggested a connection between productive learning and the gained productive knowledge. The outcomes also corresponded to the number of the target words used in writing. The productive learners outperformed the receptive learners.

As for the limitation of this study, the results may not be applicable in all the situations. In addition, some factors might have certain impact on the present study, such as students' writing experiences and vocabulary learning ability, selection of words and measurement. With regard to vocabulary and writing instruction, if the goal is to solve the deficiency of vocabulary for writing, productive learning may be more suitable than receptive learning.

\section{Conclusion}

The findings of the study supported the view that learning vocabulary productively may be superior to learning vocabulary receptively in terms of the number of the target words used, writing quality and productive knowledge of words. However, more investigation and evidence are needed for determining the relationship between vocabulary learning and writing. For further study, measurement can be extended to other domains of composition such as academic research paper, English for Specific Purposes (ESP), composition and free writing. For many EFL learners, both writing and vocabulary learning are considered to be complex and difficult tasks. Hence, different effects of vocabulary learning on writing for elementary, medium and advanced levels would also need to be examined. 


\section{About the author}

Dr. Feng-chen, Tai is currently a lecturer at Asia-Pacific Institute of Creativity in Taiwan. She has been teaching English since 2000. Her research interests include vocabulary learning and writing. Email: ashlee@ms.apic.edu.tw

\section{References}

Astika, G., (1993).Analytical assessments of foreign language students' writing. RELC Journal 24, 61-71.

Chen, C.H., \& Yeh, H.C. (2004). College student's difficulties and strategies in EFL vocabulary learning. Journal of Wufen Institute of Technology, 12, 107114,

Duin, A.H., \& Graves, M.F. (1987). Intensive vocabulary instruction as a prewriting technique. Reading Research Quarterly, $22,311-330$

Graves, M.F. (1986). Vocabulary learning and instruction. Review of Research in Education, 13, 49-89.

Henriksen, B. (1999). Three dimensions of vocabulary development. Studies in Second Language Acquisition, 21, 303318.

Joe, S. (2005). The difficulty and breakthrough of English teaching in technological colleges in Taiwan. Journal of Education Research, 138, 86-94.

Lee, S.H. (2003). ESL learners' vocabulary use in writing and the effects of explicit vocabulary instruction. System, 31, 537561.

LTTC (Language Training and Testing Center), Taiwan. (2009). GEPT Elementary Writing Rating Scale Descriptors. Retrieved October 14, 2009, from http://www.lttc.ntu.edu.tw/ gepte.htm.

McDaniel, M.A., \& Pressley, M. (1984). Putting the keyword method in context. Journal of Educational Psychology, 76, 598-609.
McDaniel, M.A., \& Pressley, M. (1989). Keyword and context instruction of new vocabulary meanings: Effects on text comprehension and memory. Journal of Educational Psychology, 81, 204-213.

Muncie, J. (2002). Process writing and vocabulary development: comparing lexical frequenct profiles across drafts. System 30, 225-235.

Nation, I. S. P. (2001). Learning vocabulary in another language. Cambridge: Cambridge University Press.

Nation, I. S. P. (2003).Vocabulary in Nunan, D. (ed.) Practical English Language Teaching: New York, McGraw Hill, 129-152.

Prince, P. (1996). Second language vocabulary learning: The role of context versus translations as a function of proficiency. Modern Language Journal, 80, 478-493.

Schmitt, N. (2000). Vocabulary in language teaching: Cambridge: Cambridge University Press.

Waring, R. (1997).A study of receptive and productive learning from word cards. Retrieved January 20, 2010, from http:/ / www.robwaring.org/papers / wordcard.html

Webb, S.A. (2005). Receptive and productive vocabulary learning: the effects of reading and writing on word knowledge. Studies in Second Language Acquisition, 27 (1), 33-52.

Webb, S.A. (2009). The effects of pre-learning vocabulary on reading comprehension and writing. Canada Modern Language Journal, 65 (4), 441-470.

Yonek, L. M. (2008). The effects of rich vocabulary instruction on students' expository writing. Unpublished EdD dissertation, University of Pittsburgh, U.S.A. 
Word pairs learning

\begin{tabular}{|l|l|}
\hline on diet & 減肥 \\
\hline three months later & 三個月後 \\
\hline make fun of & 取笑 \\
\hline Fruit & 水果 \\
\hline Overweight & 過重的 \\
\hline junk food & 垃圾食物 \\
\hline keep fit & 保持身材 \\
\hline Cola & 可樂 \\
\hline Fat & 肥的 \\
\hline Vegetables & 蔬菜 \\
\hline go jogging & 慢跑 \\
\hline Laugh & 笑 \\
\hline Decide & 決定 \\
\hline Fries & 薯條 \\
\hline go swimming & 游泳 \\
\hline give up & 放棄 \\
\hline Exercise & 運動 \\
\hline Steak & 牛排 \\
\hline lose weight & 減重 \\
\hline classmate(s) & 同學（們） \\
\hline
\end{tabular}

Appendix 2

\section{Test 1: A picture-based writing}

Topic: Joe was laughed by his classmates because of being fat. Write a 50-word short story based on the following three sequential pictures.

(Joe因為胖胖的身材被同學嘲笑，於是他決定開始減肥計畫，請依照下面圖示，寫一篇約 50 字的短文。）

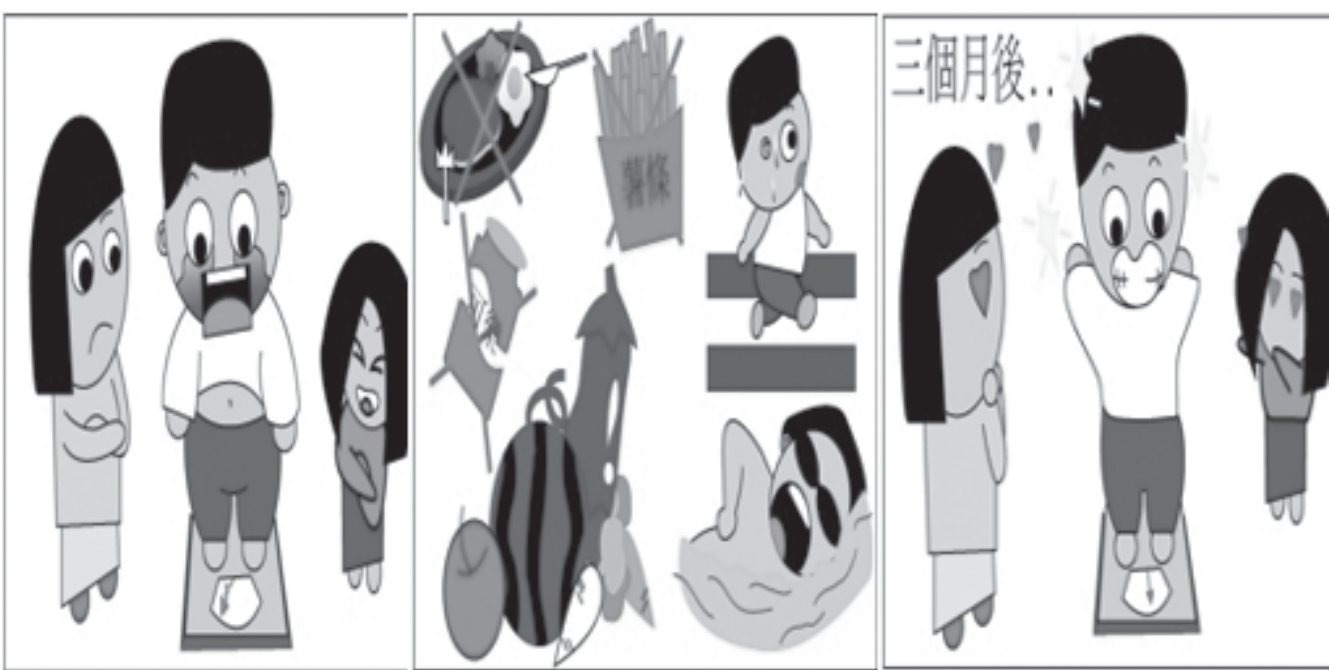

62

Journal of NELTA, Vol 18 No. 1-2, $\quad$ December 2013 
Appendix 3

Test 2: Vocabulary test on productive knowledge

班級: 姓名：學號： Group: A B (請圈選)

請依照中文寫出英文單字Please write the equivalent English words.

\begin{tabular}{|l|l|l|l|}
\hline 減肥 & & 慢跑 & \\
\hline 三個月後 & & 笑 & \\
\hline 取笑 & & 決定 & \\
\hline 水果 & & 薯條 & \\
\hline 過重 & & 游泳 & \\
\hline 垃圾食物 & & 放棄 & \\
\hline 保持身材 & & 運動 & \\
\hline 可樂 & & 牛排 & \\
\hline 肥 & & 減重 & \\
\hline 蔬菜 & 同學 (們) & \\
\hline
\end{tabular}

Appendix 4

Target words

\begin{tabular}{|l|l|l|l|l|}
\hline on diet & overweight & go jogging & go swimming & lose weight \\
three months later & junk food & laugh & give up & classmates \\
make fun of & keep fit & decide & Exercise & fat \\
Fruit & cola & fries & Steak & vegetables \\
\hline
\end{tabular}




\section{GEPT Primary Writing Rating Scale Descriptors ${ }^{\ddot{y}}$}

\begin{tabular}{|c|l|}
\hline Rating Scale & \multicolumn{1}{c|}{ Description } \\
\hline 5 & $\begin{array}{l}\text { Completelyaddress the requirements of the task; rare errors in } \\
\text { grammar and/or word choice }\end{array}$ \\
\hline 4 & $\begin{array}{l}\text { Almost address the requirements of the task; occasional errors in } \\
\text { grammar and/or word choice but do not cause difficulty for the } \\
\text { reader }\end{array}$ \\
\hline 3 & $\begin{array}{l}\text { Mostly address the requirements of the task; noticeable errors in } \\
\text { grammar and/or word choice. Cause some difficulty for the reader }\end{array}$ \\
\hline 2 & $\begin{array}{l}\text { Partially address the requirements of the task; cause } \\
\text { misunderstanding. Many errors in grammar and/or word choice; } \\
\text { cause strain for the reader. }\end{array}$ \\
\hline 1 & $\begin{array}{l}\text { Respond to one requirement of the task; excessive errors in } \\
\text { grammar and/or word choice. Severely distort the message. }\end{array}$ \\
\hline 0 & Equivalent of no answer \\
\hline
\end{tabular}

ÿThis is author's translation. 